\title{
A TRAVESSIA E A CHEGANÇA DA COMITIVA DO GLORIOSO SÃO BENEDITO DA PRAIA EM BRAGANÇA -PA.
}

Larissa Fontinele de Alencar ${ }^{1}$

Recebido em: 21/04/ 2017

Aprovado em: 10/05/2017

[...] O rio é esse batuquel Da Marujada chegando/ Espelhos, fitas, gingados/ Marujos soltos na terra / Marujos, sonho e chorado

O rio conta a vossa história / Longa história desse povo / Tristeza feito alegria / Marcada na cantoria [...]

$O$ rio é a minha cidade / Refletida sobre a tarde. [...]

Maria Lúcia Medeiros ${ }^{2}$

É preciso atravessar o rio para chegar a Bragança-PA, apesar de outros caminhos terrestres terem se constituído ao longo dos anos. A simbologia das travessias e cheganças das águas amazônicas permanecem incrustradas na tradição, em especial, na tradição da Marujada de São Benedito.

O dia oito do mês de dezembro, impreterivelmente, é marcado pelo retorno da comitiva do Glorioso São Benedito da praia à cidade de Bragança, onde é recepcionada por centenas de devotos às margens do rio Caeté, para em seguida esmolar por mais alguns dias pela cidade e entrar na igreja em que permanecerá até o próximo ano. Trata-se dos ciclos das esmolações em louvor a São Benedito, mais especificamente à Marujada de São Benedito.

São três comitivas imbuídas em arrecadar donativos e evangelizar através dos tambores e ladainhas ao santo: a Comitiva da Colônia, a Comitiva dos Campos e a Comitiva das Praias. Esta última, percebida em sua travessia pelo rio até a chegada à cidade de Bragança, enquanto as demais, que chegam à cidade pelos caminhos terrestres, adentram sem grandes esperas.

Essas esmolações atravessam matas e rios, praias e campos, ao toque do tambor que alerta os promesseiros por onde passa, são caminhos que se cruzam e se traçam a partir da fé e devoção ao santo preto. Os homens nas andanças e cantorias angariam os donativos que variam entre animais domésticos e dinheiro com o objetivo de fomentar a festividade que culmina com a grande procissão do dia 26 de dezembro. A Comitiva que vem das praias é sempre a mais ovacionada entre os devotos, pois muitos dizem que a imagem do santo por ela trazida é milagrosa e que tem seus momentos de humor, como uma estátua anímica.

\footnotetext{
${ }^{1}$ Mestre em Linguagens e Saberes na Amazônia (UFPA).

2 MEDEIROS, Maria Lúcia. Benquerença, in.: COUTO, Valentino Dolzane do (org.). Antologia da Marujada. Cadernos IAP, v. 9, Belém, 2000, p.17.
} 
$\mathrm{Na}$ tradição oral bragantina dos devotos ao santo preto, circula uma história que corrobora o dito anterior e evidencia os motivos da travessia do rio Caeté ser tão simbólica: em entrevista concedida à pesquisadora Mavilda Aliverti, em 2004, o atual presidente da Irmandade do Glorioso São Benedito de Bragança, João Batista Pinheiro, o Careca, conta que no período colonial uma embarcação atravessava o rio Caeté quando notaram um objeto em cima da proa de um barco naufragado. Era uma pequena imagem de São Benedito, que resgataram e guardaram dentro da cabine do comandante. No entanto, tempos depois a imagem sumiu e, quando os tripulantes retornaram ao lugar de onde a retiraram, ela estava lá. Por isso, resolveram estes entregá-la aos moradores da Vila-Que-Era para que erguessem uma ermida de palha ao santo, iniciando a tradição de louvação ao santo preto, São Benedito (MORAES, 2006 p. 38). Seria uma explicação para a rendição de graças e louvores ao santo, mas também algo que justifica o enaltecimento que a população de Bragança tem por este momento simbólico da travessia do rio e chegança à cidade.

\begin{abstract}
A travessia da Comitiva é sempre um grande evento, com muitos foguetes e devotos recepcionando-os à beira do cais do porto, as marujas vestem-se de saias coloridas, camisetas brancas e os pés descalços. É a demarcação de um momento de transição, o santo chega a cidade e passa a frequentar as casas daqueles que fazem parte oficialmente da Irmandade da Marujada. Também é o momento em que se encontram novamente, depois de uma longa jornada os membros da comitiva com os padres. Neste momento o padre, responsável da Diocese, conduz a imagem de São Benedito durante e travessia do rio, benzendo toda a orla do rio Caeté, na chegada faz uma benção e depois o santo é entregue aos membros da comitiva para dar continuidade ao ritual das esmolações. (ALENCAR, 2014, p. 47)
\end{abstract}

O rio metafórico de tantas cheganças, o Caeté, traz em suas águas o reflexo das embarcações de todos os tipos. Do lado esquerdo os urubus sobrevoam as carcaças dos peixes, do lado direito vê-se uma mata verde ainda sem ação do homem, e adiante, na frente da cidade, ao alto a igreja do santo preto e em seu arredor uma multidão na expectativa dos foguetes que anunciam que ele já vem.

As capturas deste ensaio fotográfico foram feitas no dia 8 de dezembro de 2016, durante o primeiro dia do evento acadêmico II Seminário Tradução e Interculturalidade. Na ocasião, um grupo de acadêmicos e pesquisadores faziam também a travessia através do rio, em dois barcos pesqueiros adaptados para o momento. Na sequência, foram feitas algumas imagens entre o traslado da beira do rio até a casa do primeiro promesseiro. Finalmente, em outro dia, ainda no decorrer do evento, a comitiva da praia adentrou no espaço do Campus universitário da UFPa, devidamente preparado para a recepção do santo. 


\section{REFERÊNCIAS}

ALENCAR, Larissa Fontinele de. NO RASTRO DOS "PÉS DESCALÇOS": da Marujada à narrativa literária. Dissertação de mestrado, Programa de Pós-Graduação de Linguagens e Saberes na Amazônia, Universidade Federal do Pará, 2014.

MORAES, M. J. P. (et al). Tocando a Memória: Rabeca. Belém: Instituto de Artes do Pará, 2006. 

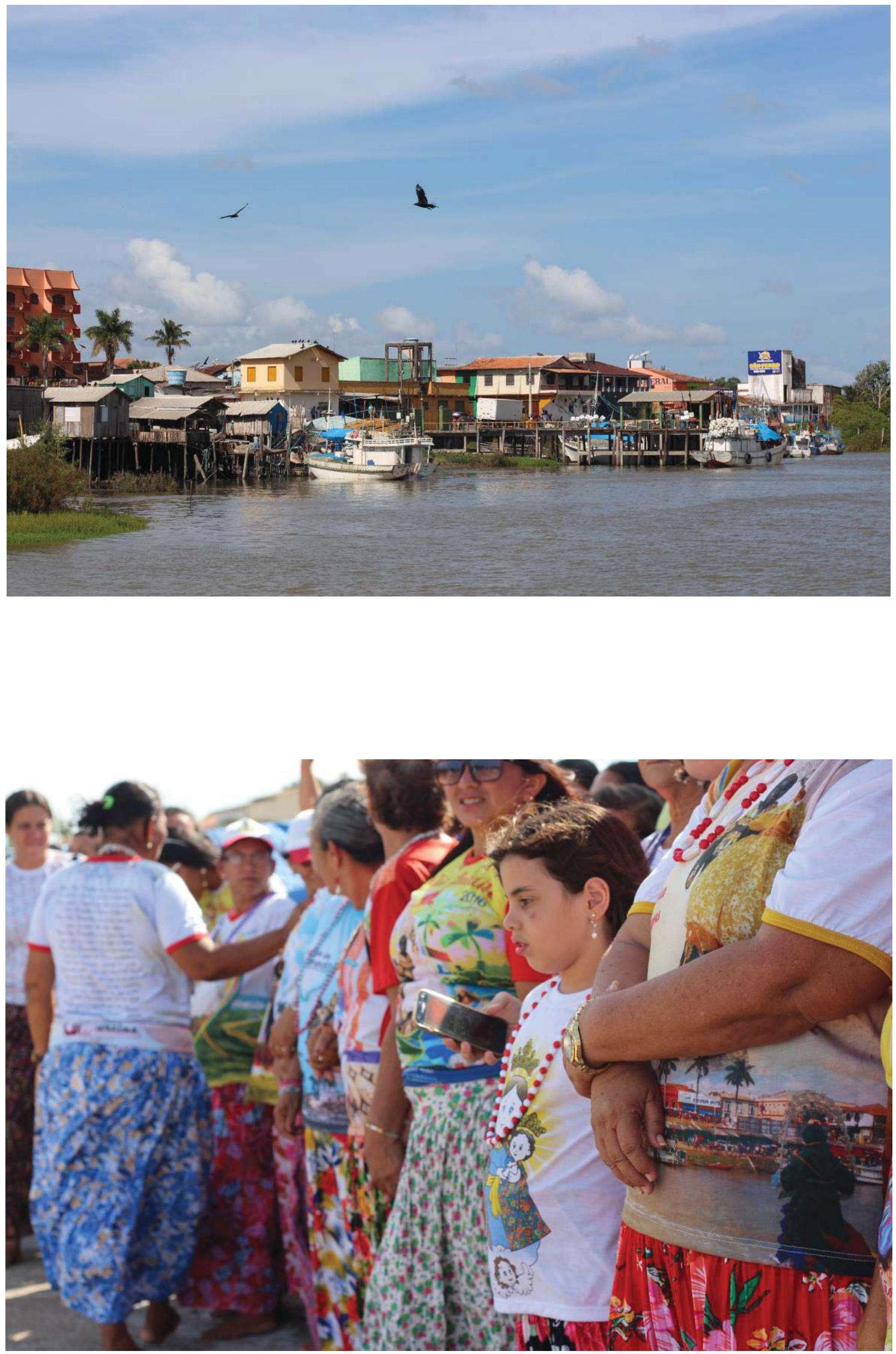

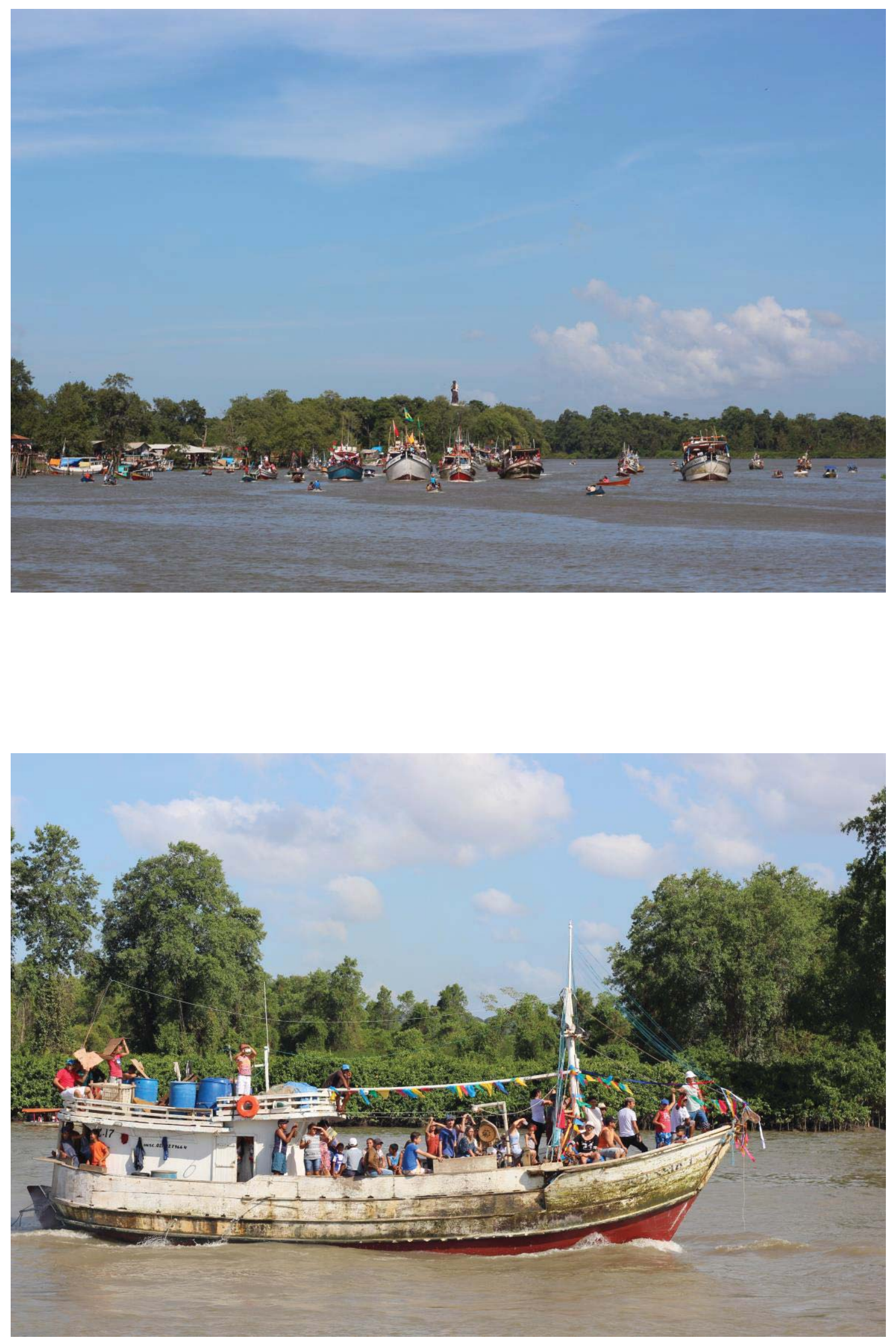

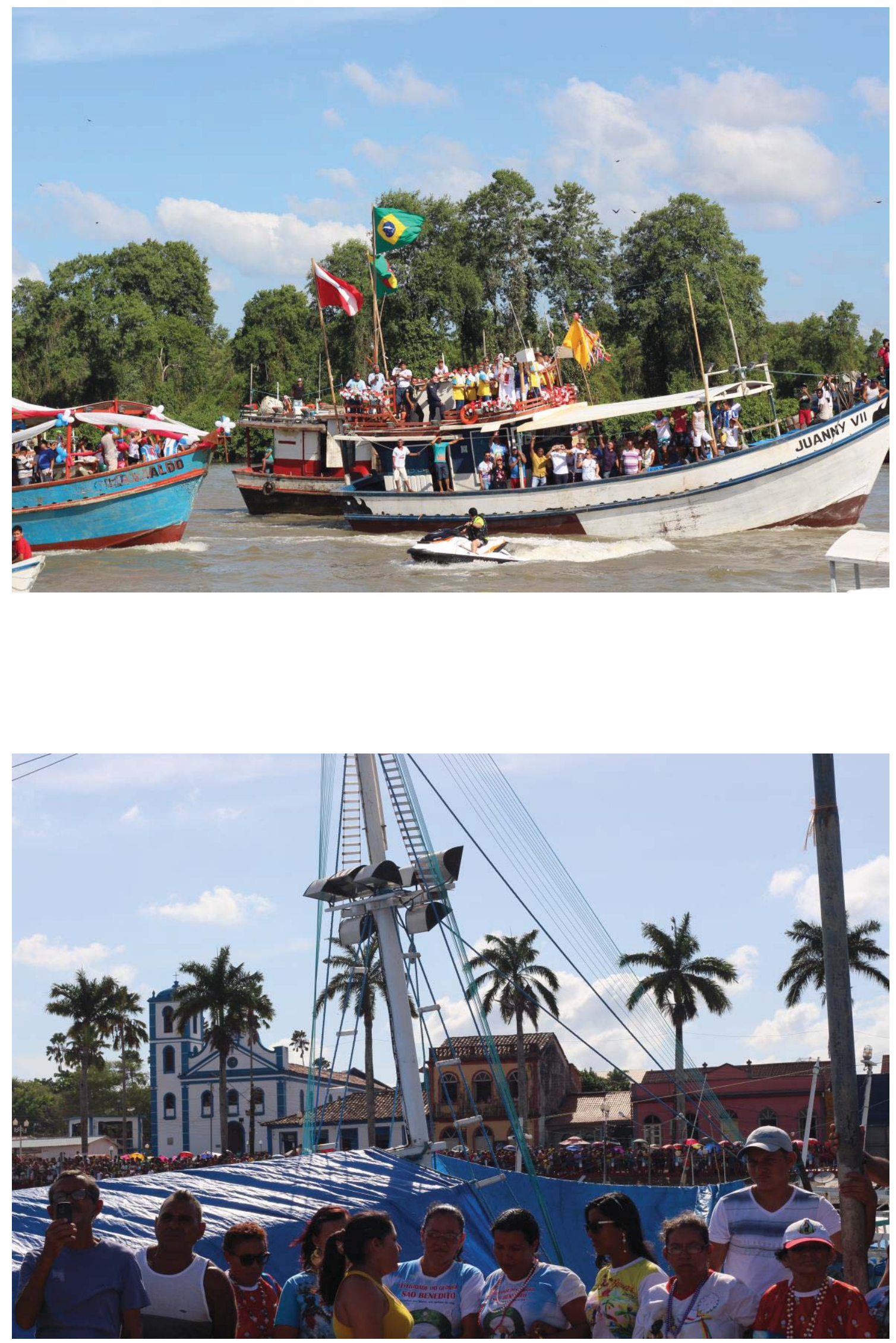

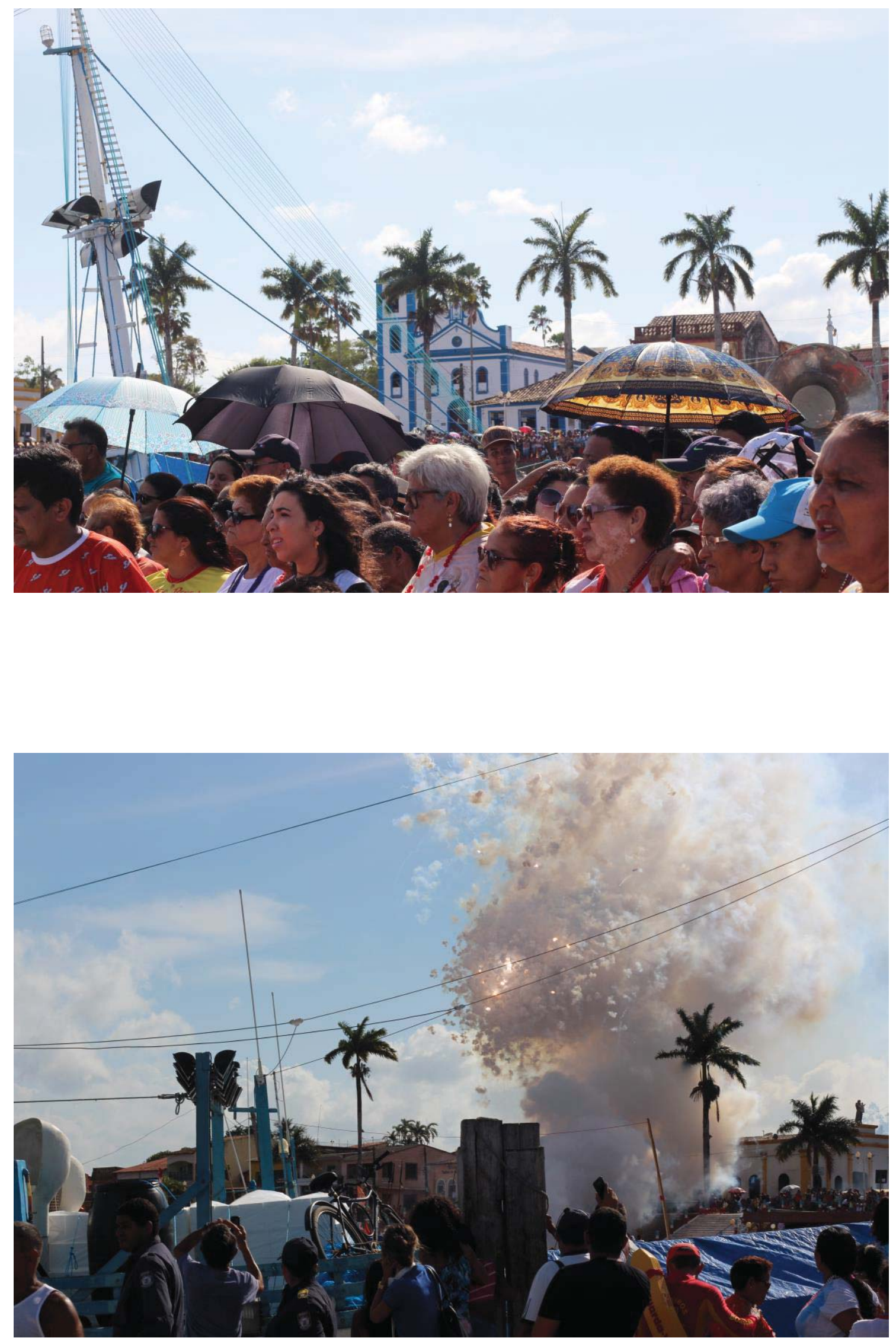

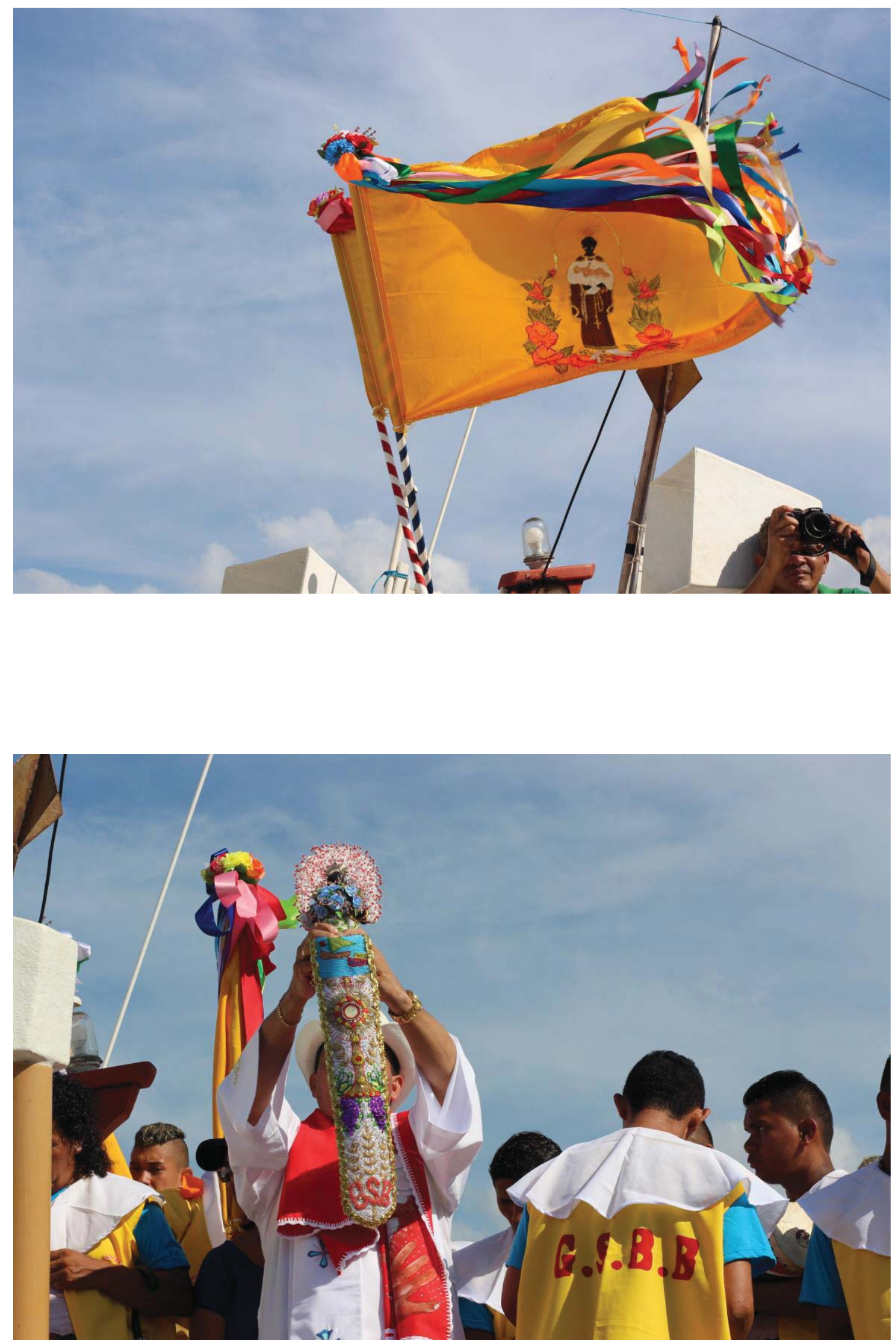

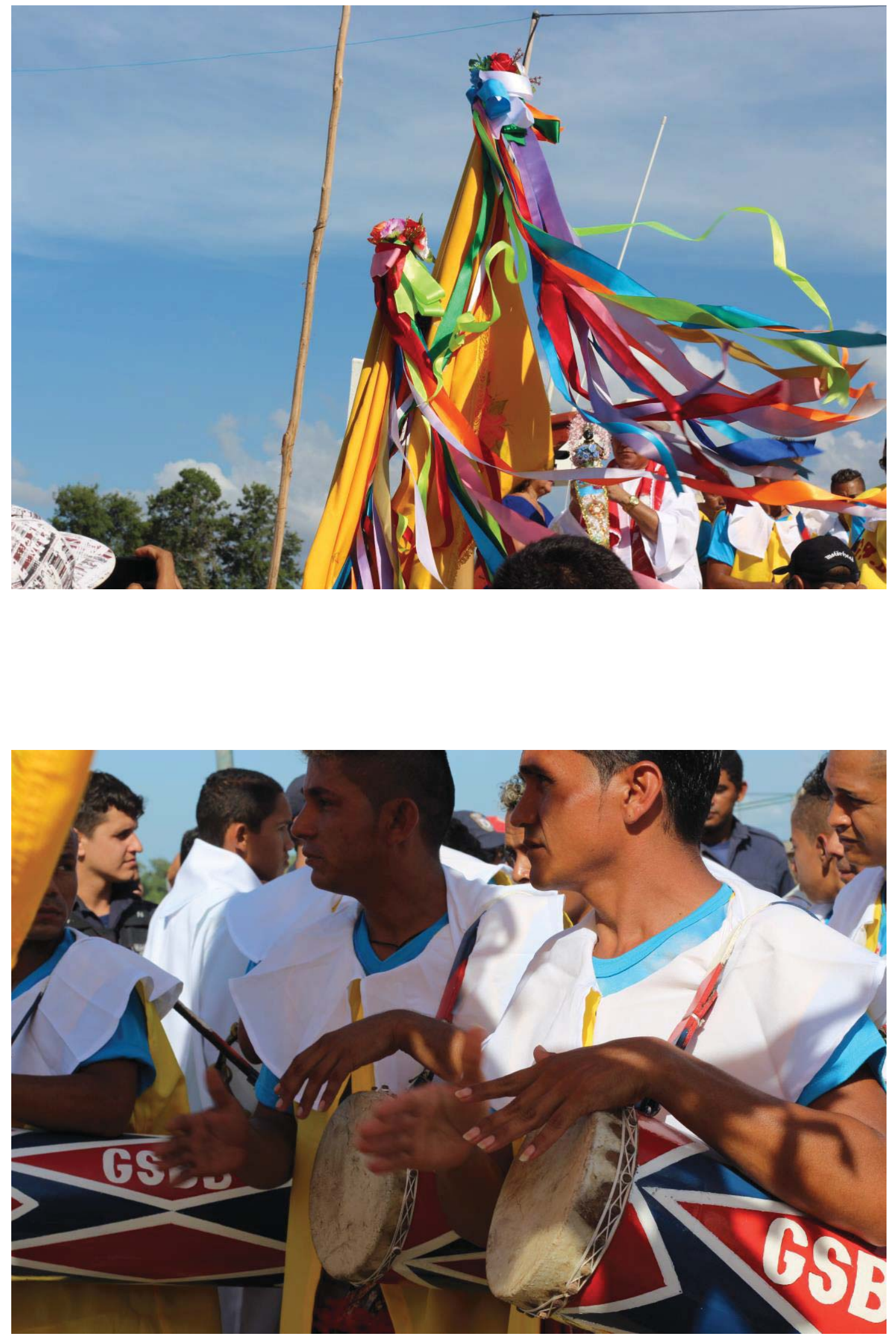

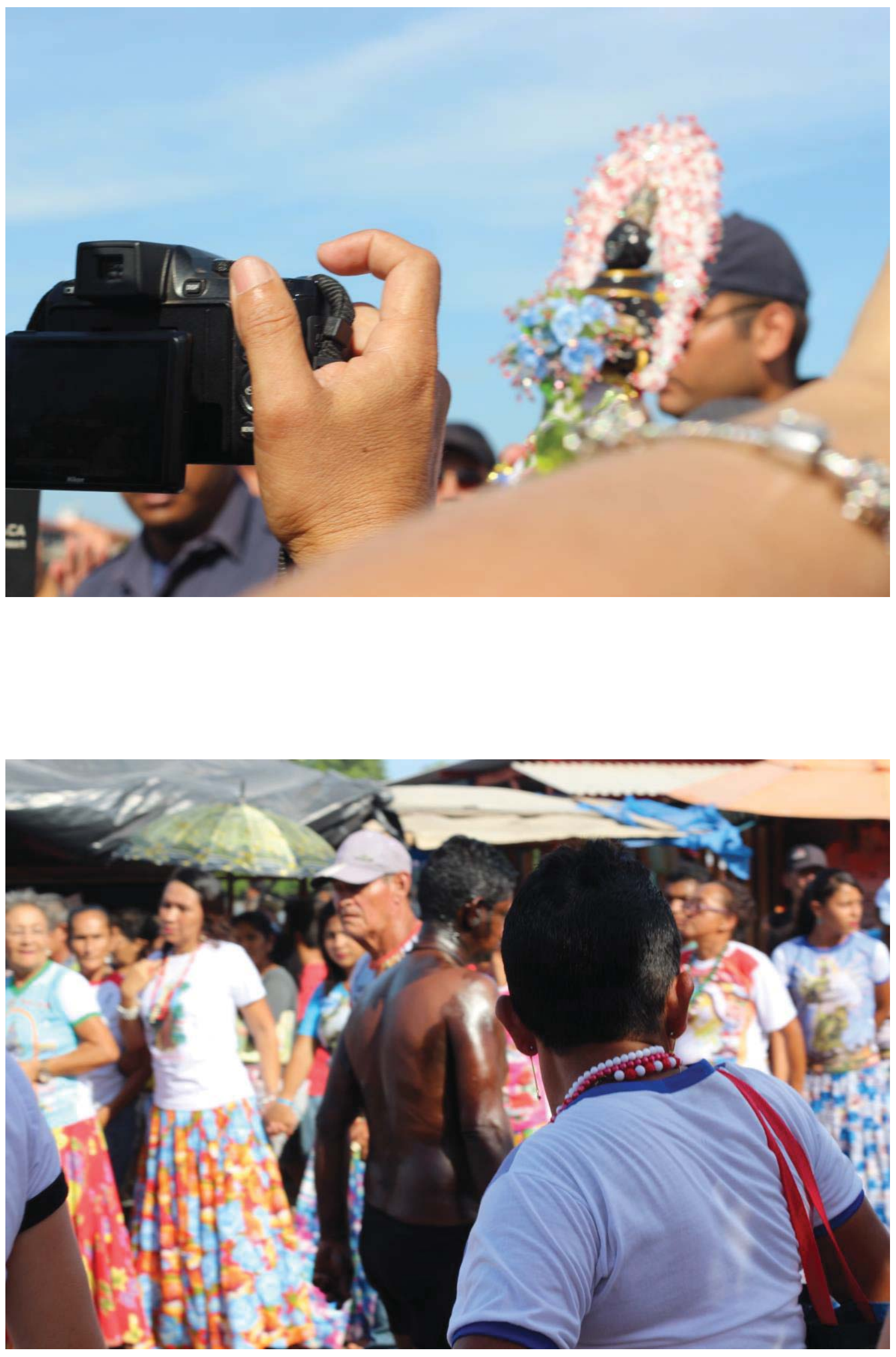

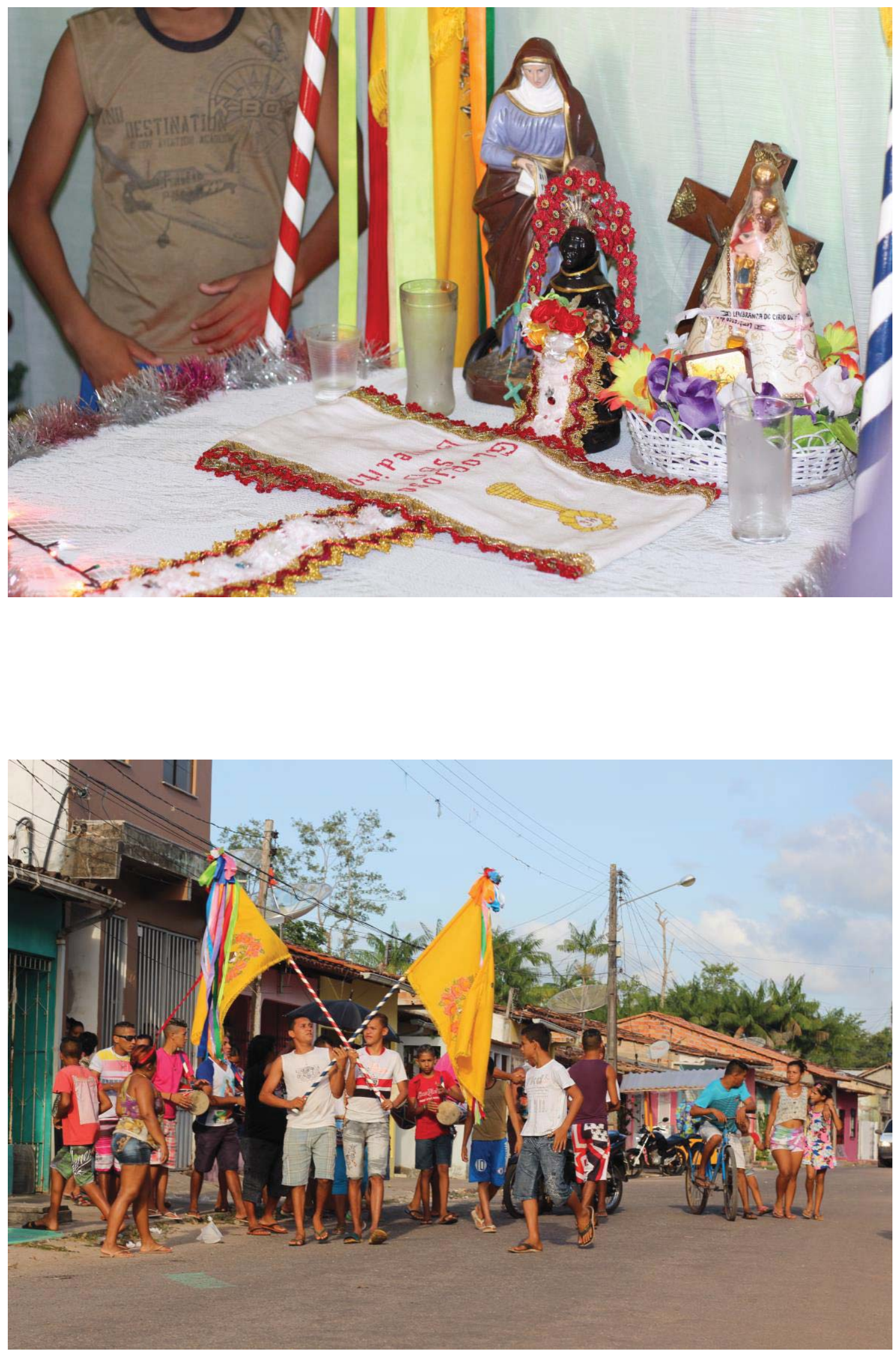

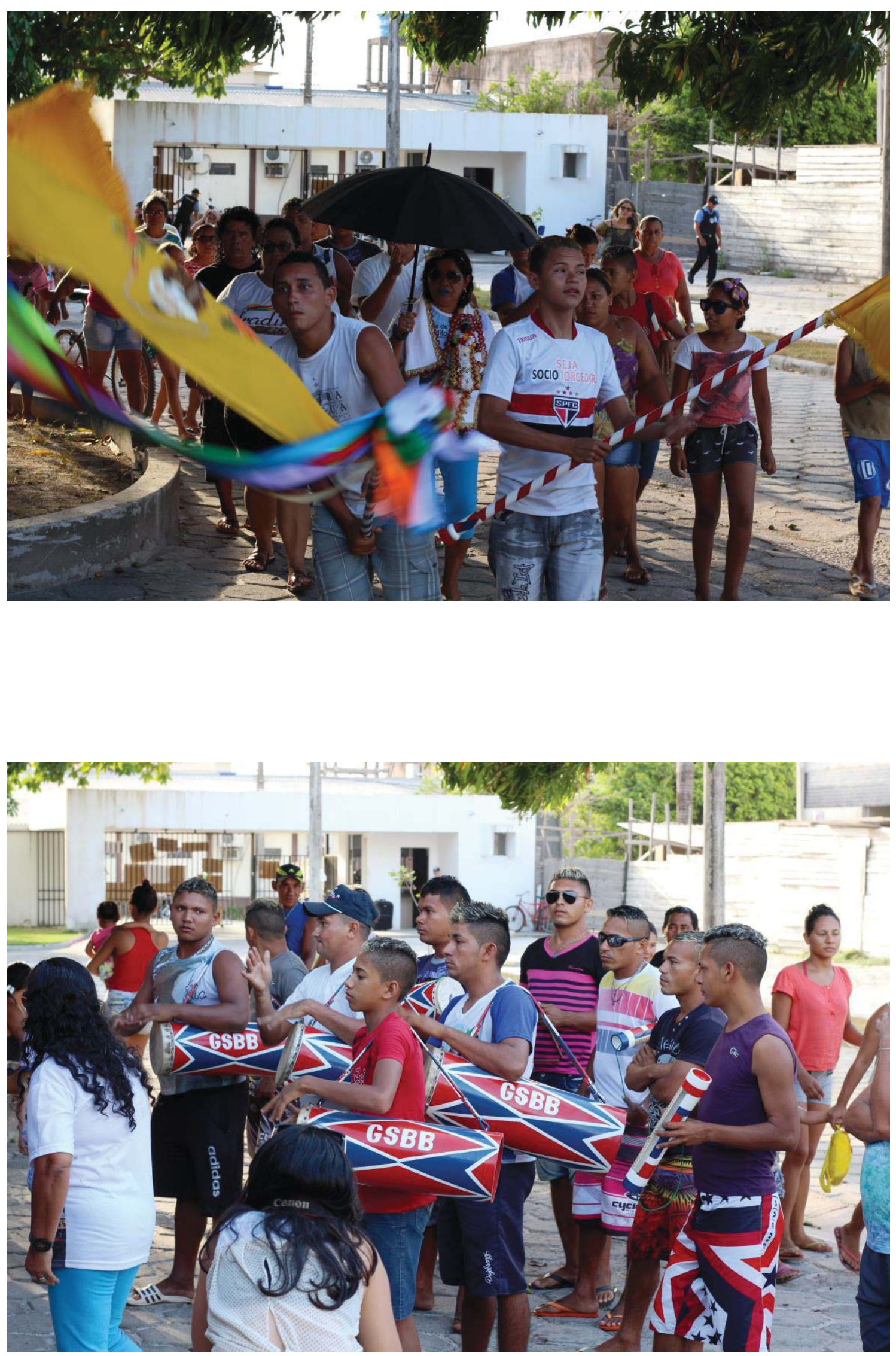

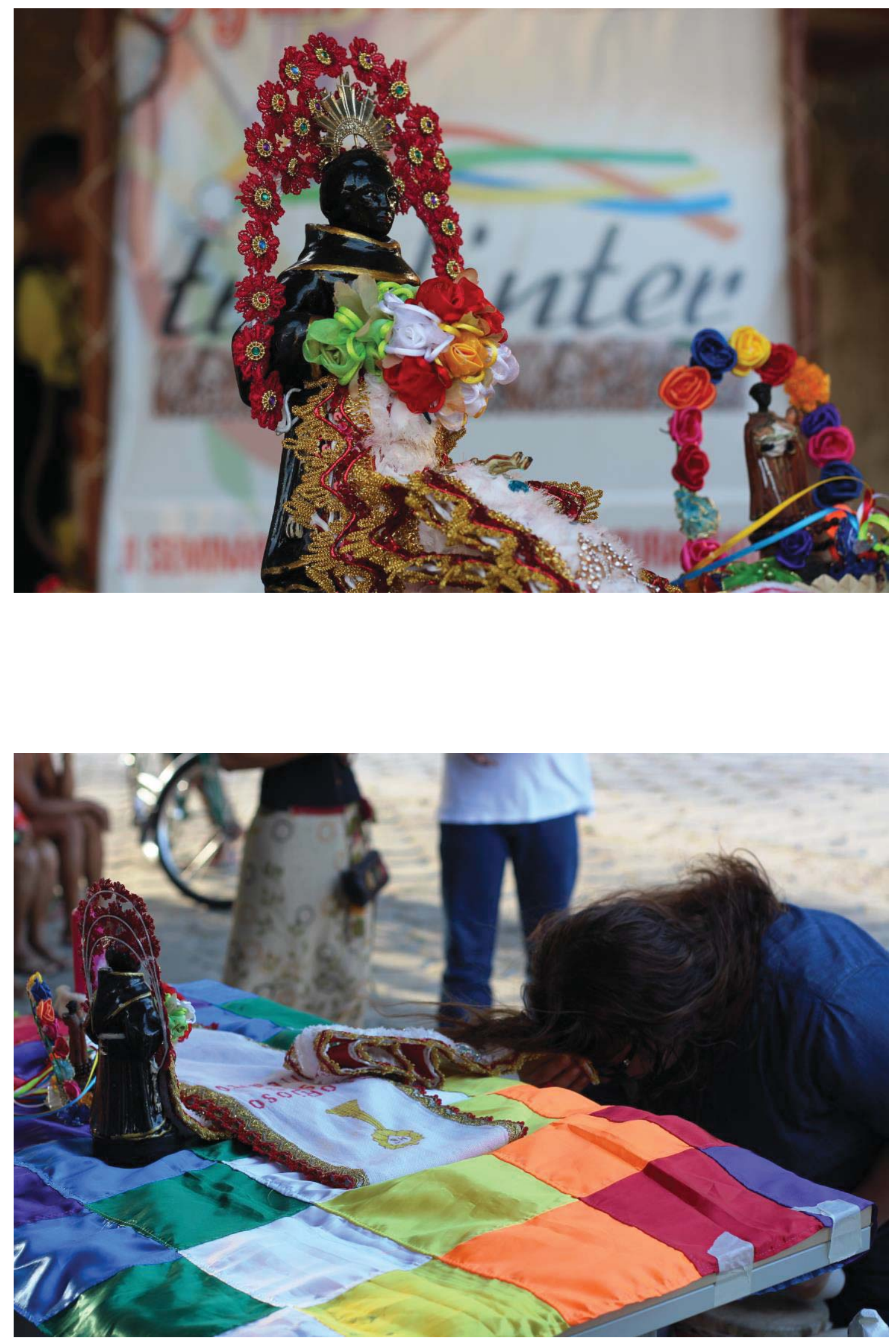